DOSSIÊ TEMÁTICO: Perspectivas para pensar as cidades: infâncias, educação, democracia e justiça

d०1 https://doi.org/10.22481/praxisedu.v16i40.6890

\title{
OS JARDINS/PARQUES URBANOS DE LISBOA PELO OLHAR DE ADULTOS E PELA AÇÃO DAS CRIANÇAS
}

\author{
LISBON URBAN GARDENS/PARKS TROUGH ADULT'S GAZE AND CHILDREN'S \\ ACTION
}
LOS JARDINES/PARQUES URBANOS DE LISBOA, POR LA MIRADA DE ADULTOS E LA ACCION DE LOS NINÕS Y NIÑAS

\author{
Eunice Castro Seixas \\ SOCIUS/CSG, Universidade de Lisboa- Portugal \\ Catarina Tomás \\ Instituto Politécnico de Lisboa \\ CICS.NOVA.FCSH NOVA - Portugal \\ Niccolò Giacchetta \\ Università IUAV di Venezia -Itália
}

\begin{abstract}
Resumo: Os jardins e os parques urbanos são espaços públicos construídos socialmente pela ação humana, nas suas múltiplas dimensões e na diversidade dos grupos sociais, culturais e geracionais que os frequentam. No entanto, o espaço urbano não tem sido compatível com a inclusão social plena de todas as crianças. Estes espaços são geralmente concebidos sem a sua participação, com base numa série de assunções e imaginários culturais e sociotécnicos sobre a infância e as crianças. Estas assunções, ao serem efetivadas no espaço público, contribuem para a estandardização e normalização das crianças nesses espaços, com implicações nos modos de administração simbólica da infância contemporânea, nomeadamente pela restrição da sua agência e práticas socioespaciais. Este artigo analisa o(s) modo(s) como crianças e adultos percebem e experienciam dois espaços públicos diferenciados da cidade de Lisboa (Portugal): o Jardim Vasco da Gama, em Belém e o Parque urbano da Quinta das Conchas, na Alta de Lisboa. Partindo de uma análise etnográfica assente na observação participante e em entrevistas qualitativas a frequentadores destes espaços e recorrendo a perspectivas da Sociologia Urbana e da Sociologia da Infância, pretende-se dar visibilidade às crianças como produtoras de conhecimento diferenciados dos adultos. Estes estudos de caso possibilitam discutir a situação da infância na cidade como revelador social, com especial incidência nos jardins/parques urbanos, enquanto espaços sociais estruturados, onde as crianças são particularmente tornadas visíveis nas interdições formais e simbólicas feitas às mesmas, mas também no modo como se apropriam do espaço público e efetivam o seu direito à cidade.
\end{abstract}

Palavras-chave: Cidade. Infância. Jardins/Parques urbanos.

Abstract: Urban gardens and parks are public spaces socially constructed by human action, in their multiple dimensions and in the diversity of the social, cultural and generational groups attending them. However, urban space planning and management have not been fully compatible with the social 
inclusion of all children. These spaces are generally designed without their participation and based on a series of cultural and socio-technical assumptions and representations of children and childhood. These assumptions, when implemented in the public space, contribute to the standardization and normalization of children in these places, with implications for the contemporary modes of symbolic childhood administration, namely, the restriction of their agency and socio-spatial practices. This article analyses how children and adults perceive and experience two different public spaces in the city of Lisbon (Portugal): Vasco da Gama Garden and the Urban Park of Quinta das Conchas. Inspired by an ethnographic approach, based on participant observation and qualitative interviews with visitors of these places and building from the perspectives of urban sociology and sociology of childhood, we aim to give visibility to children as producers of knowledge differentiated from adults. These case studies allow us to discuss the situation of childhood in the city as socially revealing, with a special focus on gardens/urban parks, as structured social spaces where children are made particularly visible through the formal and symbolic constraints that are imposed on them, but also through the way that they appropriate the public place and exercise their right to the city.

Keywords: City.Childhood. Urban Parks/Gardens.

Resumen: Los jardines y parques urbanos son espacios públicos socialmente construidos por la acción humana, en sus múltiples dimensiones y en la diversidad de los grupos sociales, culturales y generacionales que los frecuentan. Sin embargo, el espacio urbano no ha sido compatible con la plena inclusión social de todos los niños y niñas. Estos espacios generalmente están diseñados sin su participación, basados en una serie de suposiciones e imaginaciones culturales y socio-técnicas sobre la infancia y los niños y niñas. Estas suposiciones, cuando se implementan en el espacio público, contribuyen a la estandarización y normalización de los niños y niñas en estos espacios, con implicaciones para los modos de administración simbólica de la infancia contemporánea, es decir, la restricción de su agencia y prácticas socio espaciales. Este artículo analiza la forma en que niños y niñas y adultos perciben y experimentan dos espacios públicos diferentes en la ciudad de Lisboa: el Jardín Vasco da Gama en Belém y el parque urbano Quinta das Conchas en Alta de Lisboa. Partiendo de un análisis etnográfico basado en la observación participante y entrevistas cualitativas con visitantes a estos espacios y utilizando las perspectivas de la sociología urbana y la sociología de la infancia, el objetivo es dar visibilidad a los niños y niñas como productores de conocimiento diferenciado de los adultos. Estos estudios de caso permiten discutir la situación de la infancia en la ciudad como un revelador social, con un enfoque especial en los jardines / parques urbanos, como espacios sociales estructurados donde los niños se hacen particularmente visibles en sus interdicciones formales y simbólicas, pero también en la forma cómo se apropian del espacio público y afectan su derecho a la ciudad.

Palabras clave: Ciudad. Infancia. Jardines/Parques urbanos.

\section{Introdução}

Este estudo, assumindo uma natureza qualitativa e etnográfica, tem como objetivo analisar o(s) modo(s) como crianças e adultos percecionam e experienciam dois espaços públicos diferenciados da cidade de Lisboa (Portugal): o Jardim Vasco da Gama em Belém e o parque urbano da Quinta das Conchas, na Alta de Lisboa. Este trabalho insere-se num projeto 
mais amplo, o projeto CRiCity ${ }^{1}$ - As crianças e o seu direito à cidade: Combater a desigualdade urbana através do desenho participativo de cidades amigas das crianças. A metodologia qualitativa e particularmente a perspetiva etnográfica adotada possibilitou uma análise crítica dos processos de coprodução e negociação de imaginários e de relações socioespaciais pelos frequentadores daqueles espaços, procurando abarcar a complexidade e a multiplicidade dos mesmos.

A relação das crianças com a cidade e mais especificamente com os espaços públicos urbanos se tem constituído desde o final do século XX, como uma questão de investigação importante para diversas áreas disciplinares, como a Sociologia, a Geografia, a Psicologia, a Arquitetura ou o Design. Na Sociologia, o interesse crescente por esta questão deve-se, segundo Sarmento (2018; s.d), a três fatores e circunstâncias: (i) o desenvolvimento dos Estudos da Infância/Criança, e, em particular, da Sociologia da Infância (JAMES; PROUT, 1990; JAMES; JENKS; PROUT, 1998; CORSARO, 1997; SIROTA, 2001; SARMENTO, 2000), sobretudo a partir do final dos anos 80, trazendo para a agenda investigativa a condição social da infância e a criança como ator social, sujeito de direitos, com ação, vez e voz; (ii) o reconhecimento da cidade e da urbanidade como fenómenos importantes nas ciências sociais, nomeadamente na Sociologia Urbana e o estabelecimento de diálogos interdisciplinares desta com a Geografia da Infância (HOLLOWAY; VALENTINE, 2000; HOLLOWAY, 2014) e a Sociologia da Infância, possibilitando ampliar o olhar sobre a cidade e simultaneamente focalizar e desvelar espaços nem sempre reconhecidos na academia como significativos, como os "espaços para crianças", o que inclui os jardins e os parques; e (iii) a tematização da infância na cidade como revelador social, cultural e simbólico. Acrescentaríamos mais dois fatores, (iv) o contexto sociojurídico e histórico internacional com a promulgação e ratificação da Convenção dos Direitos da Criança (ONU, 1989) que reconhece a crianças como sujeito de direitos, o que inclui o direito à cidade; e (v) a ação de movimentos, iniciativas e experiências que têm permitido colocar na agenda mediática e pública a inclusão das crianças na/para centralidade urbana (por exemplo, Orçamentos Participativos com crianças e jovens, Cidades Amigas das Crianças, Cidades Educadoras, Parlamentos Jovens, entre outras).

O reconhecimento social, político e investigativo do lugar das crianças na cidade tem vindo a ganhar espaço, sobretudo por via de dois discursos de sentidos contrários: por um lado, um discurso que reivindica o direito das crianças à cidade, no seu acesso, usufruto e reinvenção,

${ }^{1}$ Para saber mais sobre o projeto CRiCity (Ref. IP PTDC/SOC-SOC/30415/2017) financiado pela Fundação para a Ciência e a Tecnologia (FCT): https://socius.rc.iseg.ulisboa.pt/cricity/ 
tentando combater políticas contemporâneas de planeamento e gestão urbanística onde os espaços para crianças tendem a ser iguais e quase nunca pensados com as crianças. Por outro lado, temos um discurso crítico em relação à forma como as crianças têm sido afastadas das cidades, seja por via da sua institucionalização (SARMENTO, 2004; 2018), seja por via da insularização (ZEIHER; ZEIHER, 1994; HENGST, 2007; LEVERETT, 2011), ou ainda por via de um conjunto de paradigmas e imagens associados à infância e às crianças, como o paternalismo, a propriedade, a proteção, o controlo e a periculosidade (TOMÁS, 2007).

O discurso do risco na e da infância tornou-se um discurso dominante e os espaços paracom crianças não são imunes a esse discurso. O retraimento das crianças na cidade, sobretudo por circularem maioritariamente entre ilhas urbanas (ZEIHER, 2003), sobretudo a familiar e a educativa, é uma realidade. $\mathrm{O}$ atropelo aos direitos da criança é também aqui uma realidade, porque é-lhes cerceado o direito de vivenciar a cidade na sua plenitude, de ter tempo ao tempo livre, de ter tempo a brincar nos espaços públicos e ter autonomia de escolha e circulação. As crianças tornaram-se habitantes menores da cidade ocidental da pós-modernidade e do neoliberalismo. Mais, os espaços públicos urbanos a elas destinados, como jardins e parques, assumem-se, cada vez mais, como espaços circunscritos, estruturados, controlados, homogéneos e avessos a qualquer tipo de risco (JENKS, 2005; GILL, 2007; MATTHEWS; LIMB; TAYLOR, 1999; 2000; SCOTT; JACKSON; BACKETT-MILBURN, 1998). Não obstante, o acesso e a utilização daqueles espaços pelas crianças (e pelos adultos) não são feitos de forma homogénea, existindo diferenças em função da posição estrutural e das condições sociais prévias nomeadamente, o género, a classe social, a etnia, a idade, o lugar de residência na cidade, etc.

\section{Espaços públicos na cidade neoliberal: lugares de encontro entre pessoas, culturas e espécies?}

Os parques urbanos podem ser considerados como um tipo de terceiros espaços na aceção de Oldenburg $(1997 ; 1999)$. Estes seriam espaços urbanos para além da casa e da escola, caraterizados por serem espaços de lazer e de sociabilidade, pela sua diversidade, pela assiduidade dos seus frequentadores, pelo seu ambiente relaxado e semelhante até a um 'bom lar', proporcionando conforto e suporte psicológico, por representarem o centro da vitalidade social de uma comunidade e constituírem a base da democracia. Enfatiza-se deste modo, a dimensão relacional do encontro face-a-face, num contexto de diversidade e interculturalidade. 
Pensamos que é desejável problematizar o conceito de terceiros espaços e sua adequação ao estudo dos espaços públicos urbanos. Por um lado, a dimensão relacional do encontro face-aface perde hoje importância face a formas de comunicação digital à distância, e espaços de fluxos, que tendem a concorrer com os espaços de lugares na cidade da informação (CASTELLS, 1989). Na cidade pós-moderna, as relações sociais são mais frágeis e temporárias e prevalece um sentimento de suspeição do outro, que associado a um ritmo acelerado de circulação, não permite a fruição dos lugares, nem o encontro interpessoal (BAUMAN, 2013).

Para além destas questões, a perspetiva de Oldenburg acerca dos terceiros espaços, pode ser criticada também com base no que esta desconsidera, ou deixa de fora, designadamente, dimensões da sociabilidade relacionadas com o não humano, por exemplo, com a tecnologia, as infraestruturas, a natureza e os animais. Só nas últimas décadas é que os sociólogos têm vindo a interessar-se por esta dimensão não humana, designadamente nos estudos da 'nova materialidade' (AMIN, 2008; FOX; ALLDRED, 2016) e do pós-humanismo (MALONE, 2016). Como refere Amin (2008, p. 8, tradução dos autores) "a tecnologia, as coisas, a infraestrutura, a matéria em geral deve ser considerada como um elemento intrínseco do ser humano, parte e parcela do 'social' urbano, em vez de ser considerado como um domínio separado com influência insignificante ou extrínseca nos modos de ser humano". Nesta perspetiva, critica-se a ênfase dada às dinâmicas de interação interpessoal no espaço público, em detrimento de outras dimensões materiais e tecnológicas, e das relações entre as pessoas e a materialidade.

A relação da criança com a natureza também tem sido analisada a partir de uma leitura pós-humana que desconstrói as visões antropocêntricas da ciência moderna. Karen Malone (2016), uma autora chave do pós-humanismo nos estudos sobre as crianças, critica o novo movimento "crianças na natureza", por este ter por base assunções antropocêntricas, concetualizando a criança como separada da natureza e romantizando as gerações passadas em que as crianças tinham mais autonomia para explorar a natureza. Esta romantização do passado acaba por reforçar uma visão das crianças das gerações atuais como deficitárias de comportamentos de risco, de contato com a natureza, de autonomia, ao mesmo tempo que em grande medida, se colocam a culpa nos pais e nos seus estilos parentais.

Para Amin (2008), o entrecruzamento do humano com o não humano, que o autor apelida de 'multiplicidade situada', seria mais passível de ser observada em espaços públicos que integram determinadas caraterísticas: abertos, com uma frequência grande e diversificada, pouco regulamentados e pautados pela improvisação e pela incompletude. Tais espaços fazem 
lembrar a descrição que Coser (1967) fez de um sistema urbano elástico, pouco regulado, onde a diferença é privilegiada e o conflito pode ser expresso de modo aberto e direto, que contrasta com um tipo de espaço rígido, normalizado e homogéneo, que reprime o conflito e aumenta a distância social entre as pessoas e grupos sociais. Se a cidade produzida à luz dos princípios neoliberais, tem desenvolvido estes dois tipos-ideais de espaço urbano, atualmente tende a prevalecer o segundo tipo, um espaço rígido, normalizado e homogéneo.

$\mathrm{Na}$ nossa perspetiva, todos estes estudos contribuem para a problematização e a complexificação dos espaços públicos urbanos enquanto lugares de encontro. Fazem-no, por um lado, salientando a multiplicidade de tipos de espaços públicos existentes e o modo como as políticas e os processos de gestão urbana impactam nos mesmos. Por outro, revelando a diversidade de interações que se podem analisar nos mesmos espaços: interpessoais, intra e intergeracionais, ou interculturais e a interações entre humanos e espécies não humanas. Sugerimos ainda que a análise dos espaços públicos urbanos como lugares de encontro implica necessariamente uma perspetiva desde dentro, que vise a compreensão dos modos como as diversas gerações os experienciam e os coproduzem.

\section{Modos de relação da criança com o espaço: lugares das crianças como lugares de liberdade}

Sabemos que as identidades das crianças são constituídas no espaço e através do espaço (HOLLOWAY; VALENTINE, 2000), que as crianças são capazes de uma compreensão crítica e compreensiva do espaço e também que estas interpretam, usam e apropriam os lugares de modo diferente dos adultos (BARTOS, 2013; CHAWLA, 1992; CHRISTENSEN, 2004; HACKETT, 2016; KORPELA; KYTTÄ; HARTIG, 2002; LIM, BARTON, 2010; MALONE, 2015; 2016; MATHEWS, 1992; RASMUSSEN, 2004; SCANNELL; COX; FLETCHER; HEYKOOP, 2016; SCOURFIELD; DICKS; HOLLAND; DRAKEFORD; DAVIES, 2006).

Sem pretendermos fazer aqui uma revisão exaustiva desta literatura, parece-nos importante referir que, a nível internacional, os estudos realizados têm realçado várias dimensões e diferentes focos de análise do modo como as crianças se relacionam com o espaço, designadamente: uma dimensão física onde o corpo, as sensações e o movimento surgem como centrais (KOLLER; FARLEY, 2019; HACKETT, 2016; SCANNELL; COX; FLETCHER; HEYKOOP, 2016); uma dimensão emocional e afetiva, associada a sentimentos, memórias e experiências especiais de ligação ao lugar [place attachment] (CHAWLA, 1992; MATTHEWS, 
1992); uma dimensão cognitiva relacionada com processos simbólicos e criativos (DOVEY, 1990; DERR, 2002; FETTES; JUDSON, 2010); uma dimensão mais social, que revela como as práticas espaciais são também práticas socioespaciais que permitem que as crianças deem um sentido ao mundo social onde se inserem (CHRISTENSEN, 2004; HARJU, 2013) e negociarem e testarem os limites impostos pela supervisão parental (VALENTINE, 1997); e mais recentemente, uma dimensão que tem sido realçada pelos autores do 'pós-humanismo' respeitante ao modo como a criança se relaciona, com as espécies não humanas, designadamente, a natureza e os animais (MALONE, 2016). No âmbito deste estudo interessanos ir um pouco para além destes diferentes focos e salientar aqui dois aspetos que consideramos fundamentais para a análise da relação da criança com o espaço: (i) a ideia de lugares "das crianças" e não apenas "para as crianças" e (ii) a importância do caráter indefinido, maleável ou inacabado destes lugares, no sentido de serem lugares potenciadores de liberdade.

A ideia de "lugares das crianças" em contraposição aos "lugares para as crianças" foi desenvolvida primeiramente por Lima (1989) no seu trabalho em São Paulo em escolas e parques infantis. A autora argumenta que estes espaços infantis são frequentemente desenhados e organizados com vista a perpetuar a dominação e o poder do adulto sobre a criança. Posteriormente, num texto que ficará bastante conhecido, Rasmussen (2004) analisa estas discrepâncias entre os espaços que os adultos consideram serem para as crianças - 'espaços para as crianças' e os espaços que estas apropriam como seus - 'espaços das crianças'. Através de uma escuta das crianças por meio de técnicas visuais e narrativas, a autora revela como os "espaços das crianças" são espaços que a criança usa, onde está fisicamente, onde tem experiências especiais, aos quais atribui um significado especial e que lhe provocam sentimentos específicos. Um dos aspetos mais importantes deste texto clássico é o facto de a autora enfatizar o modo como estas várias dimensões da relação da criança com o lugar (física, cognitiva, social e emocional) formam uma gestalt que não faz sentido decompor. Um segundo aspeto é a importância que a autora dá à análise do espaço experienciado subjetivamente pelas crianças e ao posicionamento epistemológico e metodológico do investigador para a sua análise. Um terceiro aspeto é o caráter político do texto, pelo facto de a autora tecer uma crítica ao modo como os espaços 'para as crianças' têm sido planeados sem a participação das mesmas.

Vale a pena aqui fazer uma analogia com a perspetiva da tríade do espaço de Lefebvre (2000): os espaços das crianças corresponderiam ao espaço vivido - l'espace vécu. Estes apresentariam frequentemente discrepâncias com os espaços concebidos para as crianças l'espace conçu. Tal como o autor sugere que só faz sentido analisar o espaço nas relações 
dialéticas entre as componentes desta tríade - o espaço concebido, o espaço percebido e o espaço vivido, também Rasmussen (2004) sugere uma análise das discrepâncias entre os espaços para as crianças e os espaços das crianças.

Vejamos agora a segunda ideia que apontámos, dos lugares para e das crianças como lugares de liberdade. Chawla (1992) sugere que as crianças desenvolvem ligações ao lugar na medida em que estes lugares lhes proporcionam sentimentos de segurança e pertença, afiliação social e oportunidades de expressão criativa e exploração. Este processo sofre variações que decorrem do desenvolvimento infantil, sendo que para as crianças mais novas, a segurança e o sentimento de pertença são centrais. À medida que a criança vai crescendo, as oportunidades de expressão criativa e de exploração autónoma vão se tornando progressivamente mais importantes, e os lugares que a criança conhece também vão-se expandindo. Há todavia, uma necessidade que permanece ao longo da infância: "a necessidade de um espaço indefinido onde os jovens possam formular seus próprios mundos" (p. 69, tradução dos autores). Este seria um espaço de liberdade e criatividade, do jogo livre, um lugar para a criança testar a sua independência, a sua capacidade de manipulação do meio e exercer os seus direitos espaciais tais como o direito de presença, o direito de uso e ação, direito de apropriação, direito de modificação e direito de dispor do espaço [disposition right] (Lynch, 1981 apud CHAWLA, 1992, p. 69).

Este espaço indefinido seria neste sentido, potenciado pelas caraterísticas de maleabilidade/manipulação dos espaços físico e sociopolítico, um pouco na linha da descrição que Amin (2008) faz dos espaços de 'multiplicidade situada', espaços subregulados e caraterizados pela improvisação e incompletude. Tanto o conceito de 'lugares das crianças' como a ideia de um "espaço indeterminado" enquanto lugar de liberdade fundamental para o desenvolvimento infantil, enfatizam a importância de um trabalho qualitativo de escuta das crianças que é simultaneamente uma ação política, pois visa compreender em que medida, e em quais contextos as crianças conseguem exercer os seus direitos socioespaciais.

\section{Posicionamento epistemológico, opções metodológicas e questões éticas numa etnografia com crianças em dois jardins/parques urbanos de Lisboa}

Partindo de uma análise etnográfica, uma metodologia particularmente útil e reconhecida para se fazerem ouvir as vozes das crianças na produção de dados sociológicos (JAMES; PROUT, 1990; CHRISTENSEN, 2004; CORSARO, 1997; FERREIRA, 2003, 2004, 
2010), o percurso metodológico realizado assentou na observação participante e em entrevistas qualitativas realizadas com crianças e adultos em dois espaços da cidade de Lisboa: o Jardim Vasco da Gama ${ }^{2}$, em Belém (JVG) e o parque urbano da Quinta das Conchas (PQC) ${ }^{3}$, na Alta de Lisboa, em Portugal. Estes dois contextos foram selecionados pelos seguintes motivos: i) por constituírem dois espaços públicos ao ar livre, situados em diferentes zonas da cidade de Lisboa, mas ambos bastante frequentados por crianças e respetivas famílias; ii) por se tratar de casos contrastantes relativamente às caraterísticas físicas dos próprios espaços, particularmente no que respeita as áreas infantis, e ao tipo de frequentadores - maioritariamente portugueses no PQC e turistas - muitos destes estrangeiros, no JVG. Por conseguinte, estes dois espaços possibilitaram conciliar a relativa diversidade de experiências e situações analisadas com a profundidade adequada a um estudo compreensivo, incorporando o maior número possível de informações relevantes e promovendo a triangulação de fontes e de dados, com vista a um enriquecimento da compreensão da questão de investigação nas suas múltiplas dimensões e matizes.

A partir da interlocução entre a Sociologia Urbana e a Sociologia da Infância, pretendeuse dar visibilidade às crianças como produtoras de conhecimento diferenciados dos adultos, ou seja, mais um caminho que se abriu no reconhecimento das crianças como atores sociais e o combate a investigações sobre a cidade que são consistentemente seletivas no que concerne as crianças.

Um dos critérios de uma etnografia prende-se com o tempo de permanência no terreno, que no caso da investigação que aqui se apresenta, correspondeu a mais de 40 horas de observação no total, e com a utilização de técnicas associadas à etnografia, como a entrevista: foram realizadas 11 no PQC e 10 no JVG. Uma outra característica importante dos estudos etnográficos é a postura reflexiva por parte do investigador sobre o seu próprio papel no

\footnotetext{
${ }^{2}$ Este jardim, criado nos anos 1980 possui uma área de 4.2 ha. É composto por um grande relvado central e integra um pequeno parque infantil $\left(284 \mathrm{~m}^{2}\right)$ rodeado de uma vedação. Este é composto de um equipamento multifunções em madeira, em forma de castelo, com uma parede de escalada e um escorrega em inox, e de três estruturas de metal para subir ou fazer acrobacias, colocados numa superfície antichoque. O jardim possui ainda equipamento desportivo. Está aberto 24 horas e está situado em Belém, numa zona altamente turística e gentrificada de Lisboa, com bastantes acessos a nível de transportes públicos. É frequentado maioritariamente por turistas, portugueses e estrangeiros.

${ }^{3}$ A Quinta das Conchas foi reabilitada em parque urbano no ano de 2005, tendo recebido o prémio Valmor. Com uma área de 24 ha é a terceira mancha verde de Lisboa. Este parque possui uma grande zona de relvado, vários caminhos e carreiros com água e um lago. É um parque onde podemos encontrar espaços diversificados, com zonas mais contemplativas, diversas infraestruturas (dois cafés com esplanada, um auditório ao ar livre), assim como três zonas 'infantis', com equipamentos variados, mas sem existência de vedação entre as mesmas. O parque está aberto das 06:00 à 01:00 e tem bons acessos - designadamente, uma estação de metro com o seu nome. Está situado na zona do Lumiar, na 'Alta de Lisboa'. Os seus frequentadores são maioritariamente portugueses com heterogeneidade etária, a nível de classe social e de etnia.
} 
processo de investigação e nas relações que estabelece com os participantes (HAMMERSLEY; ATKINSON, 1983). Ao contrário de um paradigma positivista da investigação que considera inclusão do investigador como uma fonte de enviesamento, assume-se desde o início, que o investigador também faz parte do mundo social que analisa e tem um impacto no mesmo. No caso de os participantes serem crianças parece-nos que esta dimensão de reflexividade se torna ainda mais relevante, na medida em que se procura promover relações mais horizontais e democráticas entre adultos e crianças, a partir de uma atitude de respeito e de reconhecimento da criança como sujeito, assim como das suas múltiplas linguagens e competências. Esta atitude é parte integrante de uma dimensão ética dos trabalhos com crianças e um pressuposto fundacional dos Estudos da Infância/Criança. Com base nestes pressupostos, considerámos importante destacar aqui algumas notas reflexivas sobre o trabalho de campo e o modo como procurámos integrar essas interrogações críticas na análise.

Uma das questões fundamentais numa etnografia com crianças é, no nosso ponto de vista, a dos limites por parte dos adultos em compreender totalmente a perspetiva das crianças. Nas palavras de Aitken (2001, p. 500, tradução dos autores): "Em que medida é que a nossa posição de adultos pode invalidar a nossa capacidade de empatizar e de nos situarmos de modo autêntico nas vidas das crianças? As crianças veem coisas no meio ambiente que nós nos podemos ter esquecido de ver, muito menos compreender". Tal inquietação surgiu logo no início do trabalho de campo, quando os investigadores observavam as crianças nos parques. Por vezes, as condições meteorológicas não eram as mais propícias a um exercício de observação, que exigia estar parado durante pelo menos uma hora. Por isso, era com alguma surpresa que víamos as crianças a brincar sem casaco e aparentemente sem frio no parque/jardim, o que para nós pareciam ser períodos de tempo bastante longos, como o seguinte excerto dá conta: "Hoje havia mais gente no jardim no relvado, apesar do vento fresco que se fazia sentir [...] a temperatura até piorou e eu estava a ficar gelada mesmo com casaco. Claro que as crianças que brincavam no parque não pareciam ter frio”. (JVG, 17 de maio, 2019).

Esta nota de campo remete para uma compreensão da criança como sujeito fenomenológico diferenciado do adulto, que experiencia o mundo, o espaço e o tempo de maneira distinta. Esta questão é central a esta investigação e implicou também um reconhecimento das dificuldades e limitações da realização de entrevistas no parque/jardim. Estas interações (num formato de entrevista conversacional) foram necessariamente curtas e, por vezes, não foram possíveis de realizar porque para algumas crianças, o tempo passado a falar connosco era um tempo 'perdido', em que não estavam a brincar. Outras, mais tímidas, 
precisariam de mais tempo para se sentirem à vontade com os investigadores. Outras, por sua vez, entusiasmavam-se e notava-se que estavam a apreciar serem 'entrevistadas' e que a sua opinião fosse tida em consideração. Para além disso, a própria entrevista como momento de interação social permitiu-nos uma análise mais micro dos processos sociais intergeracionais, por exemplo, do modo como as crianças interagiam com os adultos que as acompanhavam, negociando a sua vez e voz.

Uma outra questão que suscitou algumas interrogações relaciona-se com a decisão de quem abordar. O único critério estipulado para a seleção dos entrevistados era serem adultos que estavam no parque/jardim acompanhados de crianças. No entanto, esta decisão foi condicionada pelas atividades que os adultos realizavam naquele momento, pois a investigadora sentiu-se menos à vontade para ir falar com os pais que jogavam com a bola com os seus filhos, do que para falar com os pais ou avós que se encontravam a descansar enquanto observavam as crianças a brincar. Estes últimos pareciam estar mais disponíveis para uma entrevista. Ora, esta reflexão evidencia como a seleção dos sujeitos a abordar no trabalho de campo é um processo complexo que se reveste de uma série de representações socioculturais - neste caso sobre os modos mais ou menos adequados de se abordar um estranho num espaço público, que raramente são tornadas conscientes e integradas na análise.

Ainda relativamente às entrevistas, vale a pena salientar uma outra nota de campo que permitiu tomar consciência da sua própria representação dos parques/jardins:

[...] Percebo que a minha resistência em incomodar as pessoas para as entrevistar pode estar relacionada com uma noção do tempo de relaxamento e de lazer como um tempo privado e logo a ideia de que mesmo num espaço público como este as pessoas - os adultos - querem permanecer em privado, observando os outros mas sem serem observadas e mantendo as interações pessoais a um nível mínimo. Mas simultaneamente dou-me conta de que posso ser apenas eu a projetar-me, até porque na verdade muito poucas pessoas têm recusado dar-me uma entrevista. (JVG, 17 de agosto, 2019).

A análise crítica desta disponibilidade ou resistência por parte de quem realiza as entrevistas é um outro aspeto frequentemente descurado nas investigações qualitativas, mas que pode promover uma maior compreensão do modo como este se relaciona com o campo.

Em março de 2019, iniciou-se a recolha de dados e numa primeira fase, foram desenvolvidas incursões exploratórias no terreno para análise do contexto, eventuais ajustes na seleção dos estudos de caso e adequação da grelha de análise. Após esta fase exploratória, foram realizadas observações etnográficas nos vários estudos de caso selecionados, com ênfase no JVG, com 16 observações realizadas (23h) e no PQC, com 11 observações realizadas (20h). As 
observações realizaram-se no JVG de 31 de março a 17 de agosto de 2019 e no PQC de 26 de abril a 8 setembro de 2019. Cada período de observação tinha uma duração mínima de 60 minutos, sendo a duração média de 90 minutos. As observações foram realizadas em diferentes dias da semana e ao fim de semana e em diferentes períodos do dia de modo a analisar a influência da dimensão temporal da frequência destes lugares e das práticas socioespaciais observadas. A utilização de uma 'grelha fluida' para o registo das notas de campo possibilitou incidir sobre uma multiplicidade de aspetos como: o número (médio) de crianças e adultos observados no parque naquele período; comportamentos e interações mais observados; comportamentos inesperados; tipificação de usos de espaço e de conflito de usos do espaço pelas crianças e pelos adultos; comportamentos de interação com objetos trazidos de casa, registo de conversação e de comunicação não-verbal, proxémia e descrição da área exterior circundante do parque (presença de grupos de pessoas, atividades comerciais, tráfego, acessibilidade, etc.).

As entrevistas foram realizadas durante o mês de agosto de 2019, em cada um dos contextos de análise, pela investigadora responsável pelo projeto. $\mathrm{O}$ procedimento para a realização das entrevistas foi o seguinte: a investigadora dirigia-se ao contexto de análise (PQC ou JVG) munida de gravador, guião de entrevista (em português, francês e inglês) e do formulário de consentimento informado. No local, dirigia-se a adultos que estivessem acompanhados de crianças e explicando-lhes sucintamente os objetivos do estudo e as questões relativas ao consentimento informado (descrição das atividades de participação; caráter voluntário da mesma; direito a recusar ou a abandonar a investigação, riscos, confidencialidade e contatos do projeto e da investigadora responsável), solicitava a sua colaboração para uma entrevista sobre o jardim/parque. Caso a resposta fosse afirmativa solicitava também a participação das crianças - que geralmente eram entrevistadas após os adultos e às quais explicava os objetivos do projeto e os termos do consentimento informado.

No JVG foram realizadas dez entrevistas a adultos (sete do sexo feminino e três do sexo masculino) e onze entrevistas a crianças (seis do sexo masculino e cinco do sexo feminino). Duas destas entrevistas foram realizadas em inglês, uma vez que os entrevistados eram de nacionalidade inglesa e irlandesa. Uma outra entrevista com uma criança, filha de um casal emigrado em França, foi realizada em francês, uma vez que a menina tinha poucos conhecimentos de português. A grande maioria dos adultos entrevistados tinha entre 30 e 45 anos e um tinha 64 anos de idade. A idade das crianças estava compreendida entre os 4 e os 12 anos. Dos adultos entrevistados, cinco eram turistas, sendo um (casal) de Viseu e os restantes 
residiam em França, Inglaterra (dois deles) e Angola. Os outros entrevistados residiam em Lisboa e na Área Metropolitana de Lisboa (nomeadamente em Cascais e na Amadora). Destes últimos, um casal era brasileiro e uma senhora era irlandesa. Apenas um dos entrevistados residia relativamente perto do JVG, na Freguesia da Ajuda. As profissões dos adultos eram diversificadas: um geólogo de petróleo, uma senhora desempregada; uma professora de línguas, um casal de informáticos, uma jornalista; uma hospedeira de bordo na British Airways, uma administrativa, um senhor que trabalhava na área das telecomunicações e uma senhora que disse ser 'special needs assistant'.

No PQC foram realizadas onze entrevistas a adultos (cinco de sexo feminino e seis do sexo masculino) e oito entrevistas a crianças (seis do sexo masculino e dois do sexo feminino). Alguns dos adultos entrevistados eram pais das crianças que acompanhavam, mas outros eram avós. Seis tinham idade compreendida entre os 30 e os 45 anos de idade, um tinha 59 anos, dois deles estavam na casa dos 60 e dois não revelaram a idade. A idade das crianças estava compreendida entre os 2 e os 11 anos de idade. Dos adultos entrevistados, nove residiam em Lisboa, sete dos mesmos na zona do Lumiar/Alta de Lisboa e dois residiam na Área Metropolitana de Lisboa (Loures e Alverca). Um dos entrevistados era de nacionalidade ucraniana. As profissões dos adultos eram diversificadas: um atleta de alta competição, um encarregado de obras, um engenheiro, uma empregada doméstica, um cozinheiro, uma senhora doméstica reformada, um operador de produção, um carpinteiro, um consultor e uma médica.

Após a transcrição integral das entrevistas e uma leitura sistemática quer das entrevistas quer das notas de campo, os investigadores procederam a uma análise temática qualitativa (BRAUN; CLARKE, 2006) destes dois tipos de documentos. Esta metodologia possibilitou uma descrição, síntese, interrogação e interpretação das perspetivas dos participantes, nas suas (di) semelhanças. A codificação e análise são entendidas nesta perspetiva como fazendo de um processo fluido e flexível, em grande parte indutivo, mas em que se assume um papel ativo do(s) investigador(es). A análise possibilitou identificar várias dimensões ou temas, sendo que neste artigo escolhemos desenvolver três dos mesmos: (i) Liberdade para explorar e experimentar; (ii) A Relação com os (des)conhecidos no Parque; e (iii) Dimensões 'NãoHumanas' da Sociabilidade.

\section{Liberdade para explorar e experimentar}

Um primeiro tema resultante da análise qualitativa relaciona-se com a valorização que as crianças fazem da exploração do espaço através do movimento e da experimentação, ou seja, 
a possibilidade de se moverem de um espaço a outro e de experimentarem os vários equipamentos ou as affordances disponibilizadas no parque/jardim. Trata-se de uma dimensão de apropriação do espaço que coloca a ênfase no corpo enquanto movimento, perceção e ação, permitindo à criança experienciar, conhecer e tornar seu aquele lugar (CHRISTENSEN, 2004; CHRISTENSEN; MIKKELSON, 2012; HACKETT, 2016).

O seguinte extrato de uma entrevista no PQC, mostra como as crianças passam pelos vários espaços infantis do parque e não gostam de estar muito tempo paradas num sítio. Percebemos ainda que para estas crianças, o parque não é restrito às 'zonas infantis', mas abarca o parque em geral, ganhando relevância os lugares onde costumam estar com a família e os amigos, por exemplo, a fazer piqueniques ou a jogar à bola, ou seja, as memórias surgem aqui como especialmente significativas para uma ligação ao lugar (CHAWLA, 1992).

[...] Entrevistadora: Ah, portanto, jogam futebol, fazem piqueniques e brincam aqui nestes...

Menina: Aqui, aqui e lá à frente.

Entrevistadora: Usam os equipamentos todos?

Menina: Sim.

Menino: Sim, todos. E daqui a bocado vamos para outro.

Entrevistadora: O quê? Não percebi.

Menino: E daqui a bocado, vamos para os escorregas. [...]

Entrevistadora: E o que é que tu gostas mais de fazer aqui?

Menino: Tudo.

Entrevistadora: O que é que é tudo?

Menino: Ando nos escorregas, redes... brincar ali nos comboios, que aquilo é... comboios, neste... neste parque e lá ao fundo dos fundos...

Entrevistadora: Lá ao fundo aonde?

Menino: Lá ao fundo, onde tem aquelas mesinhas, onde nos sentamos e fazemos o piquenique. (PQC_2019.08.06_02)

Centrando-nos na área do parque infantil, tanto no PQC como no JVG, tivemos a oportunidade de observar como as crianças nunca restringem a sua ação de brincar com um só equipamento, gostando de passar por vários, embora possam ter um preferido, onde ficam mais tempo. A exploração e a experimentação são outros aspetos indissociáveis deste processo de conhecimento e apropriação do espaço pela criança. A liberdade que a criança tem para explorar e experimentar é influenciada, por um lado, pelos próprios espaços do parque e o modo como estes foram concebidos e planeados, e por outro lado, é função da supervisão parental/dos adultos responsáveis que acompanham a criança. As observações que fizemos nos dois parques permitiram-nos compreender os vários matizes destas restrições impostas à criança.

O PQC possui várias áreas ditas infantis, ou seja, planeadas para as crianças, nomeadamente: a área do equipamento multifunções, destinada às crianças mais pequenas, 
seguida da zona da aranha e do comboio e um pouco mais acima, a área dos escorregas. Estas áreas são abertas, não existindo qualquer vedação em redor das mesmas, apenas zonas de relvado e caminhos, que se constituem como convites a caminhar ou a correr, duas ações fundamentais para a construção do espaço (CHRISTENSEN; O’BRIEN, 2003; HACKETT, 2016; INGOLD, 2007). Esta liberdade que as crianças têm no PQC é referida e valorizada pelos adultos entrevistados. Por exemplo, no seguinte excerto, um adulto salienta a importância do seu filho saber que existem várias opções de brincadeira no parque:

[...] Entrevistadora: O que é que acha que as crianças gostam mais deste jardim?

Pai: Ah, sei lá, toda todo o jardim é de acordo para eles. Porque lá está, eles têm mais que uma opção de brincadeira. Desde os escorregas lá em cima na parte de cima do parque aqui a esta parte dos baloiços, dos escorregas mais pequenos, da aranha até a parte da relva em que eles podem jogar à bola e desfrutar de outras brincadeiras.

Entrevistadora: E o seu filho brinca a estas coisas todas?

Pai: Ele consegue brincar com todas as situações

Entrevistadora: Vai aos diferentes espaços?

Pai: Exatamente. Pode não fazer tudo de uma só vez mas ele tem noção de que aqui pode usufruir de várias brincadeiras. (QC_ 2019:08.05.02)

A observação participante realizada no PQC suporta esta ideia de que a inexistência de barreiras físicas na zona infantil encoraja as crianças, nomeadamente as mais pequenas, a testarem a sua autonomia. De algum modo portanto, a liberdade de movimento potencia a criação de um lugar indeterminado de liberdade (CHAWLA, 1992), em que as atividades da criança são menos reguladas e o espaço é mais maleável.

Já no JVG, encontramos apenas uma zona concebida para as crianças, um parque infantil, cercado por uma vedação e de dimensões bastante restritas para o número de crianças que o frequenta, a que se somam os pais das crianças mais pequenas, que normalmente também permanecem dentro do parque para melhor vigiarem e ajudarem os seus filhos a utilizar os equipamentos. O parque oferece ainda uma extensa zona do relvado onde por vezes se veem crianças a jogar à bola ou ao disco com os pares, ou com os pais. Recentemente foram colocados alguns equipamentos desportivos, que embora não sejam especificamente para crianças são bastante utilizados pelas mesmas.

Pudemos constatar que, tal como no PQC, as crianças não se encontram apenas nas zonas infantis, embora predominem nas mesmas. Mas as barreiras físicas entre o parque infantil e o resto do jardim restringem a liberdade das crianças para se movimentarem no espaço. A vedação parece simbolizar a separação entre espaços para crianças e espaços para adultos 
(PITSIKALI; PARNELL 2019), podendo ser concetualizada também como uma forma de contenção ou de securitização das crianças em espaços considerados adequados para elas (HART, 2002). Para além disso, o desenho destes parques infantis tem por base uma objetificação do brincar, na medida em que esta atividade surge entendida como uma coisa que se pode operacionalizar e prever em vez de ser compreendida como o que verdadeiramente é, um processo altamente subjetivo, criativo e imprevisível (EBERLE, 2014; SELLERS, 2009; TRUEIT, 2006).

É pertinente salientar que esta ideia de que o lugar para as crianças é a zona do parque infantil é desconstruída pelas crianças e pelos adultos responsáveis, em ambos os parques. No entanto, observámos mais esta desconstrução no PQC do que no JVG, o que remete para a importância de uma arquitetura e design destes espaços que não demarque nem separe 'espaços para as crianças' e 'espaços para os adultos'.

\section{A relação com os (des)conhecidos no jardim/parque urbano}

Uma das dimensões que nos propusemos observar foi a dimensão da interação interpessoal e do ambiente social que se constrói nestes espaços de lazer. Esta dimensão surge na análise das entrevistas e das notas de campo como fundamental para os frequentadores destes lugares e também para compreendermos o modo como as crianças participam ativamente no processo social de construção do espaço. As observações realizadas permitiram-nos perceber que existem diferenças individuais, sociais e culturais importantes que pautam a interação social, sendo que algumas crianças brincam sozinhas e não interagem com outras, nem com desconhecidos. Estas diferenças parecem estar associadas por um lado, à personalidade da criança e por outro lado, à ligação ao lugar. Por exemplo, se os pais residem perto do parque é mais provável que o mesmo seja um lugar de encontro com vizinhos e amigos. Isto é mais comum acontecer no PQC, onde encontramos um maior número de frequentadores regulares e que habitam na zona do Lumiar, do que no JVG, cujos frequentadores parecem ser mais esporádicos, muitos deles turistas, portugueses e estrangeiros. No entanto, o padrão que emerge das observações e das entrevistas em geral é o de que a presença de outras crianças é um fator positivo e atrativo. Isto significa que um jardim ou parque é bom se é frequentado, se não está vazio de pessoas. E as crianças em particular, não parecem gostar de estar sozinhas, mesmo que brinquem sozinhas. Em vários momentos observámos, por exemplo, como o facto de uma criança ver outras a brincar num determinado equipamento, ou numa área dita infantil, torna 
esses equipamentos ou áreas mais atrativas ou desejáveis do que eram quando estavam vazios. $\mathrm{Na}$ realidade, quando estão sozinhas, as crianças parecem cansar-se facilmente dos equipamentos perdendo o seu interesse nestes, como se ilustra na seguinte nota de campo.

[...] Uma outra coisa que chamou a atenção hoje foi observar como um menino que a certa altura era o único no parque infantil, se cansa de brincar nos equipamentos sem o estímulo de outras crianças e começa a brincar de fazer de conta que dispara sobre alguém, ainda dentro do parque infantil. Até que finalmente desiste e se junta às duas senhoras adultas (provavelmente familiares) que o observam sentadas na relva. O equipamento por si, sem outras crianças não parece ser suficientemente estimulante. (Notas de Campo, 16 de maio, JVG).

A imaginação e a brincadeira de faz de conta surgem como uma maneira de tornar presente o 'outro' (um outro imaginário sobre quem o menino dispara), que fisicamente está ausente. E mesmo quando o parque infantil do JVG está cheio, talvez demasiado para as suas reduzidas dimensões, isso parece preocupar sobretudo os pais e não as crianças. Provavelmente por estarem preocupados com a segurança dos filhos num parque sobrelotado, alguns pais retiram as crianças e vão-se embora quando o parque enche - o que acontece facilmente quando por exemplo, há visitas de um jardim-de-infância local. As crianças, por outro lado, parecem saber gerir melhor a situação.

Dentro das zonas ditas infantis observámos muitas crianças a brincar com os irmãos e também com outras crianças desconhecidas, e menos interação com os pais, avós ou adultos que as acompanham, excetuando quando se trata de crianças muito pequenas que necessitam da ajuda de um adulto para usarem os equipamentos. Mas também observámos como é fundamental para as crianças sentirem que os pais/avós estão ali perto e muitas delas chamam a atenção dos mesmos para demonstrarem as suas habilidades e competências, por exemplo, para mostrarem que conseguiram subir ao equipamento multifunções no JVG ou na aranha no PQC.

Fora das 'zonas infantis', nos relvados, é mais comum observarmos as crianças a brincarem com os pais e avós, principalmente a jogar com a bola, mas também por vezes à apanhada, ou à ginástica. A bola é contudo a grande força centrípeta que promove a interação social quer entre as crianças e os seus pais/avós, quer entre crianças que não se conheciam previamente. Por várias vezes observámos como algumas crianças vendo outras a jogar com bola, logo se aproximam e procuram entrar também na brincadeira. Constatámos também uma diferença de género, pois observámos mais vezes os meninos do que as meninas a fazerem isto, 
em consonância com investigações que indicam que os meninos jogam mais à bola que as meninas (CARVALHO; SMITH; HUNTER; COSTABILE, 1990; KARSTEN, 2003).

Para além da bola, os brinquedos que algumas crianças trazem para o parque/jardim, também chamam a atenção de outras. Em seguida ilustro, a partir de um extrato das notas de campo, uma dessas situações, tal como esta foi observada no PQC.

[...] Os brinquedos (carrinhos e barcos) chamam a atenção de outras crianças. Há um grupo que se aproxima mas não toca em nada, só observa e comenta. Mas há um menino um pouco mais velho, o que vem com o avô e pede à mãe do menino se pode brincar com os carrinhos. A mãe deixa mas diz que agora o seu filho está na água e não quer brincar com os carrinhos. Ainda tenta chamá-lo mas ele não quer sair da água. Também não parece importar-se que outro menino brinque com os seus brinquedos, nem o outro menino parece importar-se de brincar sozinho. A mãe é que vai controlando a brincadeira porque a certa altura o menino quer colocar todos os brinquedos na água e a senhora explica-lhe que alguns se estragam e seleciona os que ele pode pôr na água. A certa altura em que a senhora adverte o seu filho para não ir para a zona escorregadia da água, o outro menino diz 'Não faz mal ele brincar ali. Eu também já fui para ali brincar'. (Notas de Campo, 30 de maio de 2019, PQC).

Neste caso, a criança procura a interação claramente motivada pelos brinquedos o que nos leva a pensar nestes espaços públicos como lugares onde se tornam mais visíveis também os marcadores sociais de classe, através da exibição de bens de consumo, que se ligam por sua vez a estilos de vida e revelam formas de 'capital cultural' (BOURDIEU, 1984). Mas o mais interessante é que apesar de este menino interagir mais com a adulta do que com a outra criança - que continua a brincar dentro de água, ele vai interceder por esta criança mais pequena, apoiando-a no seu processo de exploração e autonomia, ao argumentar - contra as preocupações da adulta, que é seguro brincar ali.

Numa outra ocasião, observa-se uma interação interessante entre algumas crianças de um jardim-de-infância, que ali estavam com as educadoras, e um turista estrangeiro:

[...] Hoje chamou-me a atenção a interação entre um adulto estrangeiro falava francês - e várias crianças portuguesas que não hesitaram em ser ajudadas por ele para fazer a escalada que não conseguiam fazer sozinhas e subir ao equipamento multifunções, o que as educadoras lhes tinham proibido de fazer. Portanto, as crianças do jardim-de-infância não hesitaram em interagir com um estranho e um estranho que falava outra língua, para conseguirem o que queriam. $\mathrm{O}$ homem estava a ajudar a sua filha a subir e viu-se de repente a ter que ajudar outras crianças que também o queriam fazer. E tratava-se de uma ajuda com toque físico necessário. As educadoras estavam distraídas a falar uma com a outra e quando viram o que acontecia disseram às crianças que tinham de descer. O senhor também já estava a tentar saber quem tomava conta destas crianças. (Notas de Campo, 3 de abril de 2019, JVG) 
Esta situação pode ser interpretada como uma transgressão na medida em que as crianças subiram à parede de escalada para chegarem ao escorrega, o que as educadoras lhes tinham proibido de fazer. Mas para além disso, revela como as crianças foram rápidas a perceber a sua oportunidade e não tiveram nenhum problema em usar um estranho para conseguirem fazer o que queriam.

\section{Dimensões 'não-humanas' no parque real e ideal \\ Infraestruturas de lazer no parque real e ideal}

As entrevistas realizadas em ambos os espaços revelam a valorização dos aspetos não humanos da sociabilidade em cada um destes lugares. Especificamente, a materialidade é uma das dimensões não-humanas mais referida e muitos dos entrevistados falam da importância das diversas infraestruturas do parque, desde os bancos para se sentarem, aos bebedouros, aos cafés, restaurantes e aos equipamentos para as crianças. Nas observações realizadas, a importância de algumas destas estruturas tinha sido já bastante visível. Por exemplo, as esplanadas do PQC estavam frequentemente cheias e no JVG, em dias de sol era difícil encontrar um banco vazio e sobretudo um banco que estivesse à sombra. No entanto, as entrevistas permitiram enriquecer e complementar a análise. No seguinte extrato de uma entrevista, duas crianças falam do que gostariam que o parque tivesse, e sugerem a criação de estruturas para desportos coletivos.

[...] Entrevistadora: Ok, está bem. Olha, e o que é que gostavas que o parque tivesse e não tem?

Menino: Um campo de futebol!

Entrevistadora: Ah, um campo de futebol..

Menina: Eu não, não diria isso.

Menino: Sim! E um campo de basquete...

Menina: Eu não disse isso, eu disse... se eu respondesse, eu diria: gostava que houvesse um campo de slide (QC_2019.08.06_02)

Esta forma das crianças responderem a esta questão, sugerindo mais 'coisas', mais 'equipamentos' para brincar, ou mais atividades foi bastante frequente. Embora o seu conteúdo remeta para um discurso de valorização de equipamentos infantis convencionais e de jogos estruturados comparativamente à valorização de affordances ou de jogo livre, pensamos que estas respostas têm que ser analisadas dentro do repertório conhecido pelas crianças, ou seja, é possível que as crianças não consigam imaginar algo muito diferente do que conhecem, viram ou ouviram falar. Neste sentido, talvez fosse importante um trabalho educativo prévio no 
sentido de desenvolver uma compreensão imaginativa do lugar (FETTES; JUDSON, 2010). Trata-se na realidade de potenciar a dimensão imaginativa da construção do espaço que as crianças já possuem.

Também os adultos deram valor às infraestruturas de lazer nos parques, designadamente aos cafés, esplanadas e restaurantes. A McDonald's ${ }^{4}$ surgiu em várias das entrevistas realizadas como um elemento importante dos parques, para as crianças e para os adultos:

[....] Entrevistadora: O que é que costuma fazer, quando vem ao parque?

Pai: Só ver, deixar a criança brincar, descansar um bocadinho, comer um gelado, ir à McDonald's mais, também, por causa da miúda. (VG_2019.08.15_04)

Os cafés são, na cultura portuguesa, lugares chave de sociabilidade no espaço público. A existência de cafés nos parques torna-os também mais agradáveis para os jovens e adultos permanecerem, sozinhos ou acompanhados, durante períodos de tempo mais longos. O excerto seguinte revela isso mesmo, o "ficar" algum tempo na esplanada e em contato com a natureza, possibilita um desacelerar dos ritmos da cidade moderna. O parque proporciona esse parar, esse desaceleramento do quotidiano urbano, permitindo pensar e "penetrar lentamente" nesses lugares (FORTUNA, 2018; 2019; cf. LOPES, 2007 acerca do 'andar' e da apropriação dos espaços públicos).

[...] Entrevistadora: Ah, então o que é que mais gosta? Se tivesse que dizer uma coisa que mais gosta neste parque?

Pai: A esplanada por exemplo. Eu gosto muito de estar na esplanada sim.

Entrevistadora: Desta ou da outra?

Pai: Ah, normalmente fico na outra. Quase diariamente se estiver de férias fico na outra. Vou lá tomar o meu café e fico lá um bom bocado ainda. (QC_QC_2019.08.05_02)

Os adultos também deram relevo aos equipamentos infantis, mas enquanto no PQC todos os entrevistados valorizaram a diversidade de equipamentos e áreas infantis disponíveis, no JVG, a reduzida dimensão do parque, assim como a falta de manutenção do mesmo, foram bastante apontadas.

Em suma, a materialidade é uma dimensão importante da sociabilidade nos parques/jardins e parece envolver a valorização de dois aspetos contrastantes do lazer, tal como os entrevistados o entendem. Por um lado, os adultos apreciam as estruturas que promovem o relaxamento e as atividades mais contemplativas, permitindo um desaceleramento do

4 Existe um restaurante McDonald's mesmo ao lado do JVG. 
quotidiano urbano. Por outro lado, adultos e crianças valorizam a ideia de um parque repleto de atividades, de ofertas culturais e de equipamentos infantis.

\section{As espécies não-humanas: a relação ambivalente com a natureza e os animais}

Além da materialidade, a análise temática revelou a importância da relação do humano com outras espécies não humanas, designadamente a natureza e os animais. No entanto, esta relação parece ser pautada pela ambivalência, na medida em que estas espécies não humanas ora são vistas como positivas, ora como negativas. Por um lado, a natureza é algo - e permanece visto como 'algo', uma coisa, sem agência e separada do humano - que é muito valorizado em ambos os espaços, e é principalmente no discurso dos adultos, embora tenhamos percebido através da observação participante que também as crianças valorizam a natureza, nomeadamente a possibilidade de correrem e andarem na relva, na água, ou de subirem às árvores. No PQC, os pais e avós das crianças, quando lhes era perguntado o que mais gostavam no parque, realçaram a natureza, os espaços verdes e a frescura (para além das estruturas materiais referidas anteriormente). As crianças tenderam a realçar mais os equipamentos. No JVG, a tendência repete-se embora, este parque seja visto de maneira bastante mais negativa comparativamente ao $\mathrm{PQC}$, suscitando várias críticas à falta de manutenção do mesmo, quer a nível do relvado que se encontra bastante seco, quer a nível do equipamento para as crianças, que está gasto e até é considerado perigoso.

É importante salientar que a zona verde do relvado em ambos os parques foi aquela onde observámos maior interação entre crianças e adultos, por exemplo, a jogar à bola, a jogar ao disco, a fazer piqueniques (especialmente no PQC) e a brincar com os cães. E estas atividades, designadamente o brincar e correr com os cães, também potenciam a interação entre desconhecidos. Para além dos cães, a presença de animais nos parques (como patos, pássaros e outros animais) foi valorizada nas entrevistas como importante para as crianças.

A água, um elemento muito presente no PQC, atrai as crianças e os jovens nos dias de calor, que gostam de ir brincar nos carreiros de água, mas esse comportamento também é visto com receio por alguns adultos. As preocupações com a higiene e a saúde parecem pautar estes receios dos pais, como se pode constatar no extrato de uma entrevista com um adulto:

[...] Entrevistado: Sim porque vê-se que às vezes a água está demasiado suja Entrevistadora: Ok

Entrevistado: Percebe? Nota-se às vezes o lodo mesmo. Ah, não é sempre mas nota-se, há alturas em que isso acontece, o que é um bocado perigoso como as 
crianças estão em contato com a água e os bichos, alguns insetos que há ali mortos. Depois vê-se também os animais ali. Portanto esse era um cuidado. (QC_2019.08.05.02)

Podem-se interpretar estas preocupações com a sujidade e com a saúde como estando alinhadas com um discurso neoliberal higienista em relação aos espaços públicos urbanos, segundo o qual estes devem ser homogéneos, limpos, asséticos e controláveis (ESTEVENS, 2017). O estender deste discurso ao próprio brincar da criança representa uma tentativa de domesticação do mesmo, no sentido da sua restrição a espaços circunscritos e equipamentos específicos. O brincar é deste modo considerado como uma coisa, retirando-lhe a sua potencialidade criativa e disruptiva, ou seja, retirando a possibilidade de construção de lugares indeterminados de liberdade (CHAWLA, 1992) e de espaços significativos para as crianças (RASMUSSEN, 2004; TOMÁS; FERREIRA, 2019).

Os cães surgem também de modo negativo no discurso dos adultos em ambos os parques. Estes são descritos como "um problema" ou "um perigo" porque andam sem trela e também porque sujam o parque. Neste discurso, aponta-se frequentemente "a falta de civismo das pessoas" que deixam os cães andar sem trela e açaime e sujar o parque. Na nota de campo que a seguir se apresenta podemos até perceber uma certa fúria com o facto de haver muitos cães no parque, no pressuposto de que o PQC seria um parque para as crianças e não para os cães:

[...] A água também atrai os cães e vi várias pessoas a passear o seu cão pela trela, deixando o animal ir pela água refrescando-se. E por acaso também ouvi um comentário de uma senhora que acompanhava o sobrinho de 5 anos e que dizia mais ou menos assim: "Tantos cães. Este parque é para crianças, não é para cães”. (Notas de Campo, 29 de maio de 2019, PQC)

Este desabafo da senhora em relação aos cães aponta para a existência de um conflito latente sobre esta questão, conflito esse que é raramente expresso de modo direto. Esta situação tem de ser analisada também no atual contexto político português, com a entrada em cena de um novo Partido com representação parlamentar - o PAN - Partido das Pessoas, dos Animais e da Natureza e a subsequente criação de parques para cães em algumas zonas da cidade de Lisboa. Esta ideia de que existem parques específicos para cães e que os outros parques são principalmente parques para as pessoas e para as crianças revela bem a distância de uma perspetiva pós-humana cujo foco não é o humano enquanto separado do não humano, mas a análise das redes relacionais que se estabelecem entre humanos e não humanos (MALONE, 2016; FOX; ALLDRED, 2016). 


\section{CONSIDERAÇÕES FINAIS}

Neste artigo, apresentamos um estudo qualitativo e de cariz etnográfico, cujo objetivo principal era o analisar o(s) modo(s) como crianças e adultos percecionam e experienciam dois espaços públicos diferenciados da cidade de Lisboa (Portugal): o JVG em Belém e o PQC, na Alta de Lisboa.

Sugerimos que os resultados da análise qualitativa revelam a importância dos posicionamentos epistemológico, teórico e metodológico adotados. A abordagem qualitativa etnográfica e o recurso a uma perspetiva interdisciplinar foram, no nosso ponto de vista, cruciais para a investigação da problemática da relação da criança com a cidade, permitindo uma compreensão da dialética que se estabelece entre os espaços planeados para as crianças e os espaços que são apropriados pelas mesmas e nos quais estas podem exercer os seus direitos socioespaciais. Salientamos aqui o facto de esta análise, embora centrada sobre as crianças, ter sido realizada também com os adultos, permitindo uma compreensão mais caleidoscópica das perceções e ações das próprias crianças, e do modo como o processo de construção do espaço pelas mesmas implica necessariamente o estabelecimento de relações reciprocas com os adultos e também a negociação de fronteiras e limites impostos pela supervisão parental e pelos dispositivos existentes nestes espaços. Só através da análise destas relações intra e intergeracionais e também estruturais é possível, como argumenta Mayall (2000), "localizar o estudo da infância no estudo das sociedades" (p. 247).

$\mathrm{Na}$ realidade, o facto de as crianças valorizarem a presença e a interação com os adultos nos contextos analisados, sugere que estes lugares são centrais para as relações intergeracionais, revelando ainda o modo como as relações com os adultos pautam os próprios processos de ligação ao lugar. Neste sentido, a ideia de um "lugar indeterminado" como lugar de liberdade poderá porventura ser repensando para incluir os pais no mesmo - por exemplo focando a análise nas atividades iniciadas pelas crianças e em que os pais participam. Em alternativa, é possível concetualizamos dois tipos de lugares dentro do parque/jardim - um lugar que a criança pode explorar e manipular de forma mais autónoma - esse tal lugar indeterminado de liberdade, e um lugar partilhado com os adultos - que é acionado quando a criança e o adulto interagem e brincam ou fazem outras atividades em conjunto.

A análise tornou clara a complementaridade dos dois tipos de dados recolhidos - da observação participante e das entrevistas qualitativas realizadas a adultos e crianças. Efetivamente, principalmente no caso das crianças, a observação no campo trouxe à análise 
matizes do uso do espaço que as crianças pouco valorizaram no seu discurso - particularmente o modo como estas usufruíam da natureza, como as víamos alegres a correr, por vezes descalças na relva, ou a brincarem na água, ou a subirem às árvores. Para além disso, a reflexividade dos investigadores possibilitou uma problematização das suas assunções, representações e decisões ao longo do trabalho de campo, o que levou a um enriquecimento da análise.

Se em ambos os parques, tanto as crianças como os adultos desconstruíram a ideia de que o "lugar das crianças" se restringia à zona do parque infantil, essa desconstrução foi mais forte no PQC onde observámos mais atividades de interação e de brincadeira entre adultos e crianças. Sugerimos que esta diferença pode estar relacionada com o modo como este parque foi desenhado, sem a demarcação clara entre 'espaços para as crianças' e 'espaços para os adultos', o que foi reforçado pelo discurso dos entrevistados, ao valorizarem as múltiplas valências do parque e a ausência de barreiras físicas. Por outro lado, a dimensão restrita do parque infantil no JVG surge bastante criticada pelos entrevistados e é vista pelos adultos como gerando insegurança. Estes dados sugerem que, dum ponto de vista de planeamento urbano, tem de ser dada prioridade aos processos participados, incluindo também as crianças, no desenho e na requalificação destes espaços públicos.

Parece-nos importante aqui destacar uma última dimensão resultante da análise, a da relação das crianças e dos adultos com a materialidade e as espécies não humanas. Pensamos que esta dimensão é merecedora de mais investigação. A questão da materialidade tal como surge na análise valoriza dois tipos contrastantes de infraestruturas: estruturas que possibilitam o relaxamento e a contemplação (como bancos à sombra e esplanadas) e estruturas que oferecem atividades estruturadas, particularmente para as crianças. Ora, estes dois tipos de estruturas podem ser algo incompatíveis entre si, na medida em que um parque/jardim cheio de atividades e eventos é um contexto onde é menos possível relaxar, dependendo da dimensão do mesmo.

Finalmente, a análise mostra que os encontros com a natureza e os animais são importantes para os pais e para as crianças, embora não sugerindo nunca a possibilidade destas espécies não humanas possuírem alguma agência, tal como é proposto pelo pós-humanismo. E por outro lado, a natureza e os animais surgem de modo bastante ambivalentes no discurso dos adultos, sendo vistos como positivos e também como negativos, particularmente nesta última representação, como um risco para as crianças. Esta representação ambivalente tem sido estudada, nomeadamente, no que respeita às tensões entre perspetivas instrumentais e morais da relação dos humanos com os outros animais (cf. MACNAGHTEN, 2004; SCHICKTANZ, 
2006). É necessário perceber estes dados no contexto atual das cidades ocidentais pósindustriais em que prevalece uma cultura de medo e um discurso de risco, associados a uma tendência progressiva à insularização e institucionalização das crianças em espaços fechados, circunscritos e estruturados, longe da natureza. Por outro lado, também é importante, como refere Malone (2016), não cair numa essencialização e romantização do passado, nem da relação entre as crianças e a natureza, pois os encontros da criança com o mundo natural nem sempre são positivos ou seguros.

\section{REFERENCIAS}

AITKEN, Stuart C. Playing with children: Immediacy was their cry. Geographical Review, New York, v. 91, n. 1/2, p. 496-508, 2001.

AMIN, Ash. Collective culture and urban public space. City, London, v.12, n.1, p. 5-24, 2008 .

BARTOS, Ann E. Children sensing place. Emotion, Space and Society, Dorchester, v. 9, p. 89-98, 2013.

BOURDIEU, Pierre. Distinction: A Social Critique of the Judgement of Taste. Cambridge, MA: Harvard University Press, 1984.

BAUMAN, Zygmunt. Liquid modernity. Cambridge: Polity Press, 2013.

BRAUN, Virginia; CLARKE, Victoria. Using thematic analysis in psychology. Qualitative research in Psychology, Philadelphia, v. 3, n. 2. p.77-101, 2006.

CARMONA, Matthew. Contemporary public space: Critique and classification, part one: Critique. Journal of Urban Design, London, v. 15, n. 1, p. 123-148, 2010.

CARMONA, Matthew. Re-theorising contemporary public space: a new narrative and a new normative. Journal of Urbanism: International Research on Placemaking and Urban Sustainability, London, v.8, n. 4, p. 373-405, 2015.

CARVALHO, Ana M.; SMITH, Peter K.; HUNTER, Thelma \& COSTABILE, Ângela. Playground activities for boys and girls: Developmental and cultural trends in children's perceptions of gender differences. Play \& Culture, Illinois, v. 3, n. 4, p. 343-347, 1990.

CASTELLS, Manuel. Globalisation, networking, urbanisation: Reflections on the spatial dynamics of the information age. Urban Studies, London, v.47, n. 13, p. 2737-2745, 2010.

CHAWLA, Louise. Childhood place attachments. In: Place attachment, p. 63-86. Springer, Boston, MA, 1992.

CHRISTENSEN, Pia. Children's participation in ethnographic research: Issues of power and representation. Children \& Society, London, v. 18, n. 2, 165-176, 2003. 
CHRISTENSEN, Pia; MIKKELSEN, Miguel Romero. 'There is Nothing Here for Us..!'How Girls Create Meaningful Places of Their Own Through Movement. Children \& Society, London, v. 27, n. 3, 197-207, 2013.

CHRISTENSEN, Pia; O'BRIEN, Margaret (Eds). Children in the city: Home neighbourhood and community. London: Routledge Falmer, 2003.

CORSARO, William. The Sociology of childhood. Thousand Oaks-California: Pine Forge Press, 1997.

COSER, Lewis A. Continuities in the study of social conflict. Nova Iorque: Free Press, 1967.

DERR, Victoria. Children's sense of place in northern New Mexico. Journal of Environmental Psychology, Amsterdam, v.22, n. 1-2, p. 125-137, 2002.

DOVEY, Kimberly. Refuge and imagination: Places of peace in childhood. Children's Environments Quarterly, Boulder, v. 7, n. 4, p. 13-17, 1990.

EBERLE, Scott G. The elements of play: Toward a philosophy and a definition of play. American Journal of Play, New York, v. 6, n. 2, p. 214-233, 2014.

ESTEVENS, Ana. A Cidade Neoliberal. Conflito e Arte em Lisboa e em Barcelona. Lisboa: Deriva e Outro Modo, Le Monde diplomatique - edição portuguesa, 2017.

FERREIRA, Manuela. Os estranhos 'sabores' da perplexidade numa etnografia com crianças. In: CARIA, Telmo H. (Ed.), Experiência etnográfica em Ciências Sociais. Porto: Edições Afrontamento, p. 149-166, 2003.

FERREIRA, Manuela. 'A gente gosta é de brincar com os outros meninos!': Relações sociais entre crianças num jardim de infância. Porto: Edições Afrontamento, 2004.

FERREIRA, Manuela. 'Ela é a nossa prisioneira!': Questões teóricas, epistemológicas e éticometodológicas a propósito dos processos de obtenção da permissão das crianças pequenas numa pesquisa etnográfica. Revista Reflexão e Ação, Santa Cruz do Sul:UNISC, v. 18, n. 2, p. 151-182, 2010.

FETTES, Mark; JUDSON, Gillian. Imagination and the cognitive tools of place-making. The Journal of Environmental Education, Cambridge, v. 42, n 2, pp. 123-135, 2010.

FORTUNA, Carlos. Caminhar urbano e vivências imprevistas. Revista Brasileira de Sociologia, Belo Horizonte, v.13, n. 6, p. 136-154, 2018.

FORTUNA, Carlos. Urbanidades invisíveis. Tempo Social, São Paulo:USP, v.31, n. 1, p. 135-151, 2019.

FOX, Nick J.; ALLDRED, Pam. Sociology and the new materialism: Theory, research, action. London: Sage, 2016.

HACKETT, Abigail. Young children as wayfarers: Learning about place by moving through it. Children \& Society, London, v.30, n. 3, p. 169-179, 2016.

GILL, Tim. No Fear: Growing up in a risk society. Lisboa: Fundação Calouste Gulbenkian, 2007. 
HACKETT, Abigail. Young children as wayfarers: Learning about place by moving through it. Children \& Society, London, v.30, n. 3, p. 169-179, 2016.

HAMMERSLEY, Martyn; ATKINSON, Paul. Ethnography: Principles in practice. $3^{\text {rd }}$ edition, London and New York: Routledge, 2007.

HARJU, Anne. Children's use of knowledge of place in understanding social relations. Children \& Society, London, v. 27, n. 2, p.150-160, 2013.

HART, Rogert, 2002. Containing children: some lessons on planning for play from New York City. Environment \& Urbanization, New York, v.14, n. 2, p. 135-148.

HENGST, Heinz. Metamorphoses of the world within reach. In ZEIHER, H; DEVINE, Dympna; KJORHOLT, AnneTrine; STRANDELL, Harriet. (Eds.), Flexible childhood? Exploring children's welfare in time and space. Odense: University Press of Southern Denmark, p. 95-119, 2007.

HOLLOWAY, Sarah. Changing children's geographies, Children's Geographies, Northampton, v. 12, n. 4, p. 377-392, 2014.

HOLLOWAY, Sarah; VALENTINE, Gill. Children's Geographies (Critical Geographies). London: Routledge, 2000.

INGOLD, Tim. Lines: a brief history. Routledge: London and New York, 2007.

JAMES, Allison; PROUT, Alan. (Eds.). Constructing and reconstructing childhood: contemporary issues in the sociological study of childhood. London: The Falmer Press, 1990.

JAMES, Allison; JENKS, Chris; PROUT, Alan. Theorizing Childhood. Cambridge: Polity Press, 1998.

JENKS, Chris. Journeys into Space. Childhood, Trondheim, v. 12, n. 4, p. 419-424, 2005.

KARSTEN, Lia. Family gentrifiers: challenging the city as a place simultaneously to build a career and to raise children. Urban studies, London, v. 40, n.12, p. 2573-2584, 2003.

KOLLER, Donna; FARLEY, Meredith. Examining elements of children's place attachment. Children's Geographies, Northampton, v. 17, n. 4, p. 491-500, 2019.

KORPELA, Kalevi, KYTTÄ, Marketta; HARTIG, Terry. Restorative experience, selfregulation, and children's place preferences. Journal of Environmental Psychology, Amsterdam, v. 22, n. 4, p. 387-398, 2002.

LEFEBVRE, Henri. A produção do espaço. Paris: Editions Anthropos, 2000.

LEVERETT, Stephen. Children's spaces. In: FOLEY, Pam; Leverett, Stephen (Eds.). Children and young people's spaces: developing practice. Houndsmills: Palgrave Macmillan, 2011, p. 9-24.

LIM, Miyoun; BARTON, Angela Calabrese. Exploring insideness in urban children's sense of place. Journal of Environmental Psychology, Amsterdam, v. 30, n.3, p. 328-337, 2010.

LIMA, Mayumi Souza. A cidade e a criança. São Paulo: Nobel, 1989. 
LOPES, João Teixeira. Andante, andante: tempo para andar e descobrir o espaço público. Sociologia: Revista da Faculdade de Letras da Universidade do Porto, Porto, v. 17, p. 69-80, 2017.

MACNAGHTEN, Phil. Animals in their nature: A case study on public attitudes to animals, genetic modification and 'nature'. Sociology, London, v. 38, n. 3, p.533-551, 2004.

MALONE, Karen. Children's rights and the crisis of rapid urbanisation: Exploring the United Nations post 2015 sustainable development agenda and the potential role for UNICEF's Child Friendly Cities Initiative. The International Journal of Children's Rights, Leiden, v. 23, n. 2, p. 405-424, 2015.

MALONE, Karen. Reconsidering children's encounters with nature and place using Posthumanism. Australian Journal of Environmental Education, Cambridge, v. 32, n. 1, p. 42-56, 2016.

MATTHEWS, Michael Hugh. Making Sense of Place: children's understanding of largescale environments. Lanham, MD: Barnes \& Noble Books, 1992.

MATTHEWS, Hugh; LIMB, Melanie; TAYLOR, Mark. Reclaiming the Street: The Discourse of Curfew. Environment and Planning A. Oxford, v. 31,n. 10, p. 1713-1730, 1999.

MATTHEWS, Hugh; LIMB, Melanie; TAYLOR, Mark. The street as the thirdspace. In: S.HOLLOWAY, Sarah; VALENTINE, Gill (Org.). Children's Geographies: Playing, Living and Learning. New York: Routledge, 2000, p. 119-138.

MAYALL, Berry. The sociology of childhood in relation to children's rights. The International Journal of Children's Rights, Leiden, v. 8, n. 3, p. 243-259, 2000.

OLDENBURG, Ray. Our vanishing third places. Planning Commissioners Journal, Burlington, v. 25, n. 4. p. 6-10, 1997.

OLDENBURG, Ray. The Great Good Place: Cafés, Coffee Shops, Community Centers, Beauty Parlors, General Stores, Bars, Hangouts, and How They Get You Through The Day. New York: Marlowe \& Company, 1999.

PITSIKALI, Alkistis; PARNELL, Rosemary. The public playground paradox:'child's joy'or heterotopia of fear?. Children's Geographies, Northampton, v. 17, n. 6, p.719-731, 2019.

RASMUSSEN, Kim. Places for children - children's places. Childhood, Leiden, n.11, p. 155-173, 2004.

SARMENTO, Manuel. Os Ofícios da Criança. Congresso Internacional - Os mundos sociais e culturais da infância. Actas vol. II. Braga: IEC/Uminho, 2000.

SARMENTO, Manuel. Infância e cidade: restrições e possibilidades. Educação, Porto Alegre, v. .41, n. 2, p. 232-240, 2018.

SARMENTO; Manuel. Nota sobre a criança e a cidade. IN: Simpósio UNESP, s.d.

Disponível em: https://tinyurl.com/wn9czxo. Acesso em 10 nov. de 2019. 
SCANNELL, Leila; COX, Robin S.; FLETCHER, Sarah; HEYKOOP, Cheryl. "That was the last time I saw my house": The importance of place attachment among children and youth in disaster contexts. American Journal of Community Psychology, Macon GA, v. 58, n. 1-2, p. 158-173, 2016.

SCHICKTANZ, Silke. Ethical considerations of the human-animal-relationship under conditions of asymmetry and ambivalence. Journal of Agricultural and Environmental Ethics, Haarlem, v. 19, n. 1, p. 7-16, 2006.

SCOTT, Sue; JACKSON, Stevi; BACKETT-MILBURN, Kathrin. Swings and Roundabouts: Risk Anxiety and the Everyday Worlds of Children. Sociology, Manchester, v. 32, n. 4, p. 689-705, 1998.

SCOURFIELD, Jonathan; DICKS, Bella; HOLLAND, Sally; DRAKEFORD, Mark; DAVIES, Andrew. The significance of place in middle childhood: qualitative research from Wales. The British Journal of Sociology, London, v. 57, n. 4, p. 577-595, 2006.

SELLERS, Marg. A rhizo-poiesis: Children's play (ing) of games. Complicity: An International Journal of Complexity and Education, Edmonton, v. 6, n. 2, 2009.

SIROTA, Régine. Emergência de uma sociologia da infância: evolução do objeto e do olhar.Cadernos de Pesquisa, São Paulo, n. 112,p. 7-31, 2001.

TOMÁS, Catarina. Paradigmas, imagens e concepções da infância em sociedades mediatizadas. Media \& Jornalismo, Lisboa, n 11, p. 119-134, 2007.

TOMÁS, Catarina; FERREIRA, Manuela. O brincar nas políticas educativas e na formação de profissionais para a educação de infância - Portugal (1997- 2017). EccoS - Revista Científica, São Paulo, n. 50, e14109, jul./set,2019.

TRUEIT, Donna. Play which is more than play. Complicity: An International Journal of Complexity and Education, New York, v. 3, n.1, 2006.

VALENTINE, Gill. 'Oh Yes I Can. Oh No You Can't': children and parents' understandings of kids' competence to negotiate public space safely. Antipode, Malden, v. 29, n. 1, p. 65-89, 1997.

VAN DEN BERG, Marguerite. City children and genderfied neighbourhoods: the new generation as urban regeneration strategy. International Journal of Urban and Regional Research, Oxford, v. 37, n 2, p. 523-536, 2013.

ZEIHER, Helga. Shaping daily life in urban environments. In: CHRISTENSEN, Pia; O'BRIEN (Ed.). Children in the city: home, neighborhood and community. London: Routledge Falmer, 2003, p.66-68.

ZEIHER, Hartmut; ZEIHER, Helga.Orte und Zeiten der Kindheit. Soziales Leben im Alltag von Grossstadtkindern. Weinheim: Juventa, 1994. 
Agradecimentos: Este trabalho é financiado por fundos nacionais através da FCT -Fundação para a Ciência e a Tecnologia, I.P.,no âmbito do projeto «PTDC/SOC-SOC/30415/2017».

\section{SOBRE OS AUTORES:}

\section{Eunice Castro Seixas}

Doutorada em Sociologia, Universidade de Coimbra (UC); SOCIUS/CSG, Lisbon School of Economics \& Management, Universidade de Lisboa- Portugal; Investigadora Responsável do Projeto CRiCity. E-mail: euniceseixas@ @ocius.iseg.ulisboa.pt

(iD http://orcid.org/0000-0001-5356-6014

\section{Catarina Tomás}

Doutorada em Estudos da Criança, Universidade do Minho (UM); Instituto Politécnico de Lisboa, Escola Superior de Educação - Portugal; CICS.NOVA, Universidade Nova de Lisboa - Portugal. E-mail: catarinatomas@ gmail.com

iD http://orcid.org/0000-0003-3713-3352

\section{Niccolò Giacchetta}

Mestre em Planificação e Política para a Cidade, o Território e o Ambiente, Università IUAV di Venezia, Itália. E-mail: niccolo.giacchetta@gmail.com

(iD) http://orcid.org/0000-0003-3536-144X 